\title{
Epidemiological Aspects of Female Urological Diseases, at the National University Teaching Hospital H. K. Maga of Cotonou from 2008 to 2017
}

\author{
Dodji Magloire Inès Yevi*, Josué Dejennin Georges Avakoudjo, \\ Dètondji Fred Jean-Martin Hodonou, Yves Nsounfou Ngapna, Jean Sossa, \\ Gilles Natchagandé, Fouad Kolawolé Yde Soumanou, Michel Michaël Agounkpé
}

University Clinic of Urology-Andrology of the National University Teaching Hospital H.K. MAGA of Cotonou (CNHU-HKM), Cotonou, Benin

Email: ^dryevi@gmail.com

How to cite this paper: Yevi, D.M.I., Avakoudjo, J.D.G., Hodonou, D.F.J.-M., Ngapna, Y.N., Sossa, J., Natchagandé, G., Soumanou, F.K.Y. and Agounkpé, M.M. (2018) Epidemiological Aspects of Female Urological Diseases, at the National University Teaching Hospital H. K. Maga of Cotonou from 2008 to 2017. Open Journal of Urology, 8, 281-288.

https://doi.org/10.4236/oju.2018.810032

Received: July 28, 2018

Accepted: October 23, 2018

Published: October 26, 2018

Copyright $\odot 2018$ by authors and Scientific Research Publishing Inc. This work is licensed under the Creative Commons Attribution International License (CC BY 4.0).

http://creativecommons.org/licenses/by/4.0/

\section{(c) (i) Open Access}

\begin{abstract}
Most urological conditions are represented by male disorders. Analyzing certain epidemiological aspects of female urological disorders at the National University Teaching Hospital of Cotnou, will allow us objectively to have reliable data to optimize the urological management of women. Patients and Methods: This was a retrospective, analytical and descriptive study that was conducted at the CNHU-HKM over a 10-year period from January 2008 to December 2017 on the epidemiological aspects of female urological diseases from the study of patient records. The variable studied was: the age, the profession, the year of admission, the organ affected, and the type of pathology. The confidentiality of the data has been ensured. Results: Female urological disorders over 10 years accounted for $9.62 \%$ of all patients received in Urology Department. The age group greater than 50 years was the most common at $31.34 \%$. Traders and housewives were the most numerous $(39.93 \%$ and $14.55 \%)$. Bladder diseases were the most frequent (51.50), dominated by vesico-vaginal fistulas $(29.85 \%)$. In addition to fistulas, tumoral affections were most prevalent at $27.99 \%$ followed by infectious diseases at $8.21 \%$. The lithiasic affections were infrequent at $6.72 \%$. Conclusion: Female urological conditions are infrequent but not negligible, dominated by vesico-vaginal fistulas and tumors in the context of developing countries. The specific evaluation of each pathology group can help optimize management.
\end{abstract}

\section{Keywords}

Female Urological Diseases, Vesico-Vaginal Fistulas, Cotonou, Benin 


\section{Introduction}

The urological diseases include those affecting the urinary and genital systems of man and the urinary system of women. For a long time, urology has been considered as a specialty dedicated to the male subject alone. The female urological pathology is not at least, because it includes a large number of diseases that can be subject to specialization. Like the pathologies of the urinary tract of the human, those of the urinary system of the woman concern the affections of the bladder and the urethra for the lower urinary system [1], and the kidneys and ureters diseases for the upper urinary tract. A large place is generally made for uro-gynecological conditions with, at the top of the list, obstetric fistulas. In the literature in general and in the urology department of the CNHU HKM of Cotonou particularly, there is no study specifically dedicated to the urological pathologies in women. That's why the authors propose through the present hospital study to appreciate the epidemiological aspects of the management of urological diseases in female subjects at the University Andrology Urology Clinic (Urology Department) of the National University Teaching Hospital Hubert Koutoukou MAGA (CNHU-HKM) of Cotonou which receives only the adult urological pathologies.

\section{Patients and Methods}

This is a retrospective, analytical and descriptive study on the epidemiological aspects of urological disorders managed at the CNHU-HKM in Cotonou over a period of 10 years from January 2008 to December 2017. All the women consulted during the 10-year study period were included in the study, which records are complete. A counting sheet was established to collect data recorded in patient admission records as well as medical records for hospitalizations during the study period. The general objective of this study was to summarize female urological pathologies at the CNHU-HKM in Cotonou, and more specifically to describe their epidemiological aspects, to classify them, to determine and compare to their hospital incidence. The variable studied was: the age, the profession, the year of admission, the organ affected, and the type of pathology. The confidentiality of the data has been ensured.

The analysis of the data was carried out with the Epi info software version 7.2.2.6 and the tables and figures made with Excel 2010 and Word 2010 softwares. The authors declare that there is no conflict of interest.

\section{Results}

We collected a total of 268 files that we analyzed on 2783 files, realising $9.62 \%$ of female hospitalizations in the service in 10 years. Figure 1 shows the distribution of patients received according to age. The age group found mostly is the one of more than 50 years old (31.34\%). Women over the age of 40 make up more than half $(56.34 \%)$ of the female patients managed in the Urology Department of CNHU HKM. 
Figure 2 shows the distribution of patients by occupation. There is a predominance of women traders (39.93\%), followed by housewives (14.55\%); the occupation was not specified in $16.04 \%$ of cases; officials and women farmers accounted for $10.82 \%$ and $9.70 \%$ respectively.

Figure 3 shows the distribution of patients by years of admission. The highest peak of this curve is in 2012 with 67 patients while the lowest peak was noted in 2008 with 2 patients.

Table 1 shows the distribution of patients according to the organ affected. There is a clear predominance of bladder disease (51.50\%), followed by renal affections (34.00\%). Ureteric disorders account for $10.8 \%$ of the female pathology in the service.

Table 2 shows the distribution of patients according to vesical pathologies. The bladder conditions are dominated by vesico-vaginal fistulas $(57.97 \%)$ followed by bladder tumors (24.64\%).

Table 3 shows the distribution of patients according to renal affections. They come second with frequencies and are dominated by tumors (37.36\%), followed by infections (18.68\%).

Figure 4 shows the distribution of patients according to ureteric disorders. They were mainly represented by iatrogenic ligation of the ureters at $34.48 \%$, followed by ureteral lithiasis at $27.59 \%$.

Urethral disorders are rare, and especially represented by tumors with 6 case on the 10 cases found.

Table 4 shows the distribution of patients according to pathologies and organs affected. Vesico-vaginal fistulas (80 cases), classified among the other pathologies brings to $43.28 \%$ this group of pathologies. Next come tumors (27.99\%), infections (8.21\%) and trauma (7.84\%).

Table 1. Distribution of patients according to the organ affected.

\begin{tabular}{ccc}
\hline Pathologies & Frequency & Percentage \\
\hline Kidney & 91 & $34.00 \%$ \\
Ureter & 29 & $10.80 \%$ \\
Bladder & 138 & $51.50 \%$ \\
Urethra & 10 & $3.70 \%$ \\
Total & $\mathbf{2 6 8}$ & $100.0 \%$ \\
\hline
\end{tabular}

Table 2. Distribution of patients according to vesical pathologies.

\begin{tabular}{ccc}
\hline Vesical pathologies & Frequency & Percentage \\
\hline Intra-vesical foreign body & 1 & $0.72 \%$ \\
Cystocele & 7 & $5.07 \%$ \\
Vesico-cutaneous fistula & 1 & $0.72 \%$ \\
Vesico-ileal fistula & 1 & $0.72 \%$ \\
\hline
\end{tabular}




\section{Continued}

\begin{tabular}{ccc}
\hline Vesico-uterine fistula & 1 & $0.72 \%$ \\
Vesico-vaginal fistula & 80 & $57.97 \%$ \\
Urinary stress incontinence & 1 & $0.72 \%$ \\
Infections & 3 & $2.17 \%$ \\
Lithiasis & 2 & $1.45 \%$ \\
Malformation & 2 & $1.45 \%$ \\
Unspecified & 2 & $1.45 \%$ \\
Traumatic & 3 & $2.17 \%$ \\
Tumors & 34 & $24.64 \%$ \\
Total & 138 & $100.00 \%$ \\
\hline
\end{tabular}

Table 3. Distribution of the different pathologies affecting the kidney.

\begin{tabular}{ccc}
\hline Kidney's pathologies & Frequency & Percentage \\
\hline Hydronephrosis by rectocolic tumor by & 1 & $1.10 \%$ \\
Hydronephrosis by retroperitoneal fibrosis & 2 & $2.20 \%$ \\
Hydronephrosis by gynecological tumors & 8 & $8.79 \%$ \\
Infections & 17 & $18.68 \%$ \\
Lithiasis & 7 & $7.69 \%$ \\
Malformation & 12 & $13.19 \%$ \\
Unspecified & 5 & $5.49 \%$ \\
Traumatic & 5 & $5.49 \%$ \\
Tumors & 34 & $37.36 \%$ \\
Total & 91 & $100.00 \%$ \\
\hline
\end{tabular}

Table 4. Distribution of patients according to pathologies and organs affected.

\begin{tabular}{ccccccc}
\hline $\begin{array}{c}\text { Organs } \\
\text { Pathologies }\end{array}$ & Kidneys & Ureters & Bladder & Urethra & Total & Percentage \\
\hline Tumors & 34 & 1 & 34 & 6 & 75 & $27.99 \%$ \\
Infections & 17 & 2 & 3 & 0 & 22 & $08.21 \%$ \\
Malformations & 12 & 1 & 2 & 1 & 16 & $05.97 \%$ \\
Traumas & 5 & 11 & 3 & 2 & 21 & $07.84 \%$ \\
Lithiasis & 7 & 8 & 2 & 1 & 18 & $06.72 \%$ \\
Others & 16 & 6 & 94 & 0 & 116 & $43.28 \%$ \\
Total & 91 & 29 & 138 & 10 & 268 & $100.00 \%$ \\
\hline
\end{tabular}


D. M. I. Yevi et al.

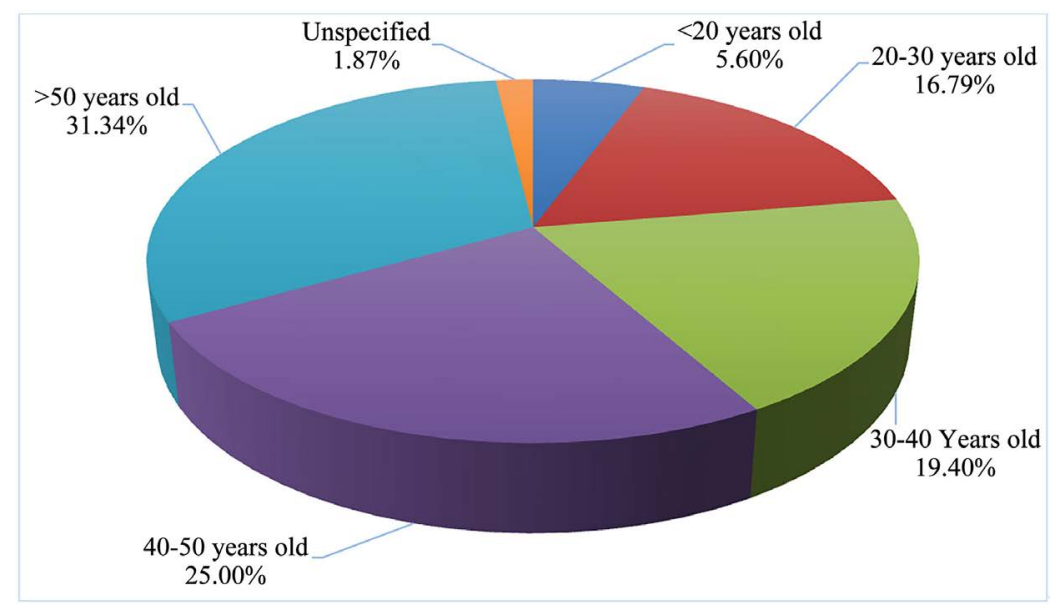

Figure 1. Distribution of patients by age.

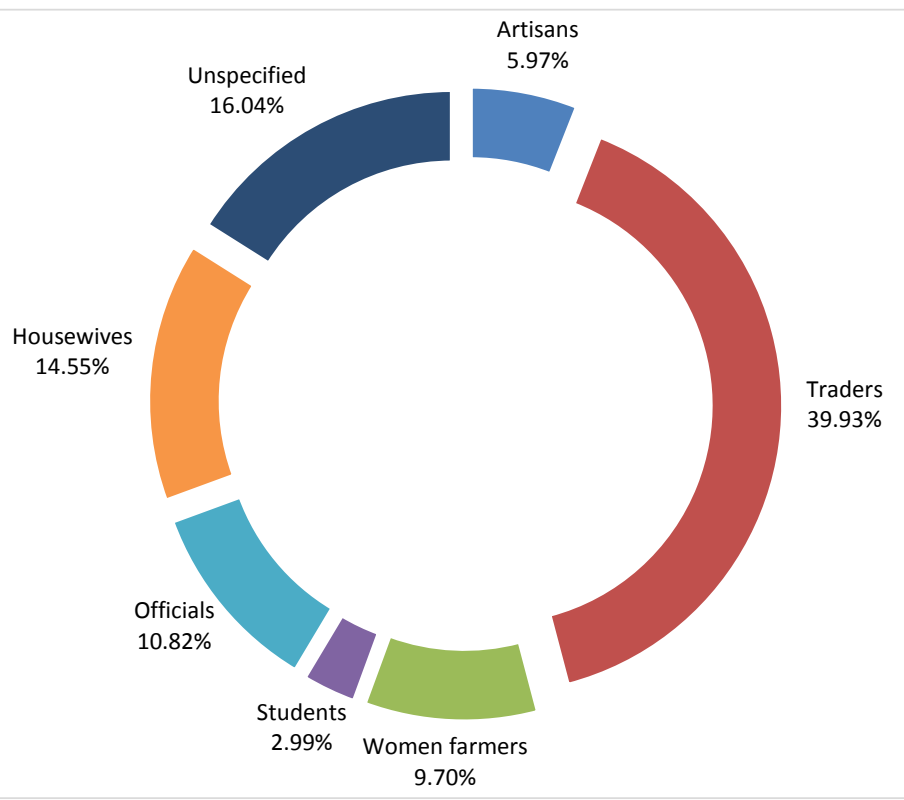

Figure 2. Distribution of patients by occupation.

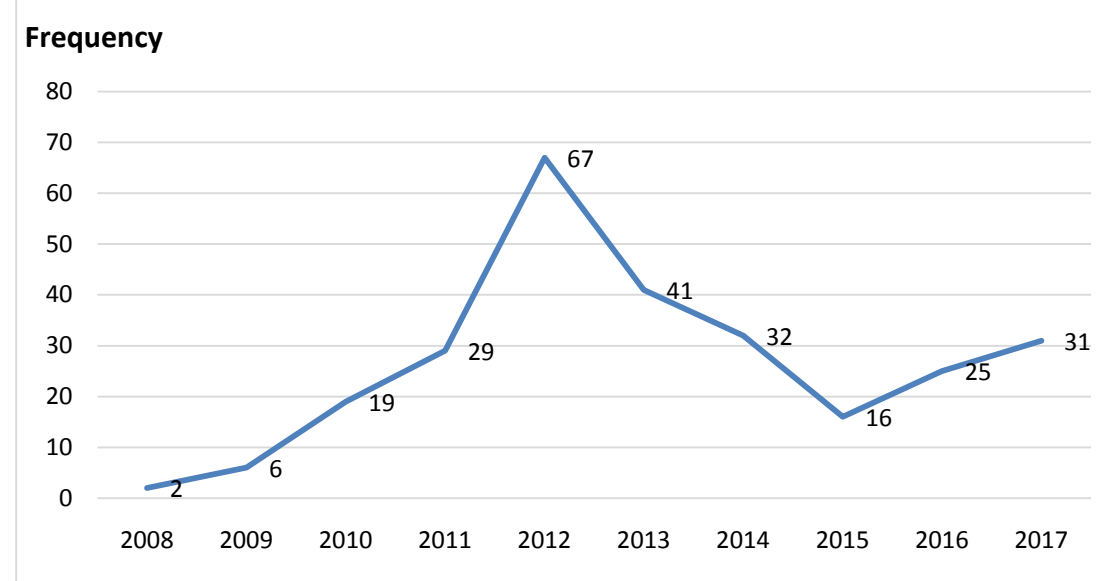

Figure 3. Distribution of patients by years of admission. 


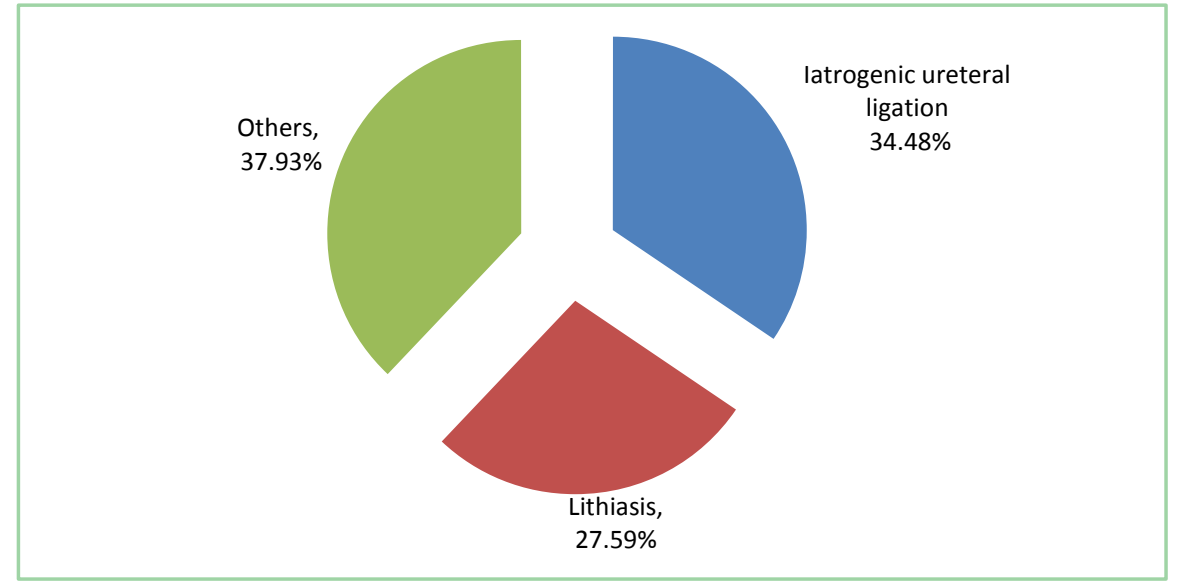

Figure 4. Distribution of patients according to ureteric disorders.

\section{Discussion}

The urology service is poorly attended by women, who represent $9.6 \%$ of the cases received over a period of 10 years. This can be explained by the fact that the urological specialty deals with the urinary system of the woman only, but in the man, it concerns the urinary system and the genital tract. The professional profile shows that women were mostly traders at $39.93 \%$, housewives at $14.55 \%$, women farmers at $9.70 \%$, which could express financial barriers to attendance at the urology department, related to the economic level.

Our results are similar to those of Matiyabo S. who found that housewives and traders were the most represented, but mostly housewives [1]. Officials accounted for $10.82 \%$, reflecting the level of education, lack of understanding of certain pathological phenomena and poor orientation in the appropriate medical service. The promotion of education, emancipation and the employment of women is essential to improve the standard of living that can contribute to the optimization of health care in our field. The large proportion of the unspecified occupation is related to the health staff, probably by omission, which is a bias to the interpretation of the level of education related to female urological conditions. Cumulative age groups of 20 to 50 years were the most numerous in our study. Bladder diseases were the most frequent and dominated by vesico-vaginal fistulas, probably related to youth and fertility. In the literature, with regard to urinary fistulas, vesico-vaginal fistulas are the most common [1]. In the study of Anoukoum T. et al. on fistulas in Togo, a 15 - 45 age group [2] close to ours was found.

Education on the prevention of vesico-vaginal fistulas would considerably reduce the hospitalization of women in the Urology Department. Fistulas are mostly found in poor Third World countries [2]. Vesico-vaginal fistulas were the most found at $29.85 \%$ of the patients. This frequency could be related to the different fistula missions performed within the Urology Department of the National University Teaching Hospital of Cotonou, in recent years. Bladder tumors accounted for $24.64 \%$ of bladder conditions after vesico-vaginal fistulas. The age 
group over 50 years is the most common. Bladder tumors occur after age 60 [3] [4] and may partly explain the high frequency of this tumor in this age group in our patients. Bladder tumors are the second most common tumor, any gender confused in the Urology service of CNHU-HKM, but more common in men [5]; this result is similar to the result found in the study of SOW M. et al. in Cameroon [6]; they also represented the 2nd most common pathology on all women's pathologies after vesico-vaginal fistulas in our series. Renal diseases come second in frequency after bladder conditions; they are essentially renal tumors (with the same values as bladder tumors on all female affections) and infectious diseases. Kidney tumors are the third most common urological tumor after prostate and bladder cancer [7]. Diagnosis of bladder and kidney tumors is usually made after the age of 50 [7]; the cumulative proportion of bladder and kidney tumors is important in our series and could therefore justify the fact that the age group over 50 is the highest. Infectious renal pathologies were poorly represented. Kidney infections are the second most common kidney disease. Urinary tract infections are common in women because of the shortness of the female urethra [8]. Women over 50 years were the most represented, corresponding to menopausal women, period where the second peak frequency of urinary infections in women is found, the first being at the beginning of sexual activity [8].

The most frequent ureteral pathologies were iatrogenic ligation of the ureters and ureteral lithiasis, respectively. Iatrogenic trauma of ureter occurs during pelvic, abdominal or peritoneal surgery, as well as during laparoscopy or ureteroscopy [9]. Lithiasis affects women less than men [10]. In our study, lithiasis was rare in other sites, although it is slightly more frequent in the ureteral area where the usual clinical manifestation is renal colic [7].

Urethral affections in women were rare, and especially represented by tumors with 6 cases on the 10 cases found. The study didn't appreciate if those tumors were secondary or primary.

At the end of the study, vesico-vaginal fistulas were the most recovered with a rate of $29.85 \%$, followed by renal tumors at about $12.68 \%$; the infections follow with $08.21 \%$, the traumas with $07.84 \%$ and the lithiasis, $06.72 \%$. Urogenital trauma is the set of open or closed lesions resulting from aggression of the urinary and/or genital tract [11]. Urogenital trauma is rare and less common in men compared to women in the Kambou $\mathrm{T}$ study [11]. This proportion of trauma is low in our context.

\section{Conclusion}

The hospital attendance of the urology service by women is very low compared to men's. Women over the age of 50 were in majority. By excluding from our series vesico-vaginal fistulas associated with Fistulas missions at the Urology department of CNHU-HKM, tumoral pathologies represent the most frequent reason for hospitalizations followed by infectious and lithiasic pathologies. The specific evaluation of each group of pathologies would be interesting to provide 
an optimal strategy of care and prevention.

\section{Conflicts of Interest}

The authors declare no conflicts of interest regarding the publication of this paper.

\section{References}

[1] Matiyabo, S. (2000) La pathologie du bas appareil urinaire de la femme adulte en dehors de la gravido-puerperalité. Thèse Méd. Cotonou, 805: 117 p.

[2] Anoukoum, T., Attipoub, K.K., Agoda-Koussemac, L.K., Akpadzad, K. and Ayite, E.A. (2010) Aspects épidémiologiques, étiologiques et thérapeutiques de la fistule obstétricale au Togo. Progrès en Urologie, 20, 71-76. https://doi.org/10.1016/j.purol.2009.08.038

[3] Irani, J. (2003) Epidémiologie du cancer de vessie. Progrès en Urologie, 13, 1207-1208.

[4] Roupreta, M., Neuzilleta, Y., Masson-Lecomtea, A., Colina, P., et al. (2016) Recommandations en onco-urologie 2016-2018 du CCAFU: Tumeurs de la vessie. Progrès en Urologie, 27, S67-S92. https://doi.org/10.1016/S1166-7087(16)30704-7

[5] Ouattara, A., Hodonou, R., Avakoudjo, J., Cisse, D., et al. (2012) Épidémiologie des cancers urologiques au Centre national hospitalier universitaire Hubert Koutoukou Maga Cotonou, Bénin. Analyse d'une série hospitalière de 158 cas. Progrès en Urologie, 22, 261-265. https://doi.org/10.1016/j.purol.2011.12.003

[6] Sow, M., Nkégoum, B., Essame Oyono, J.L. and Nzokou, A. (2006) Aspects épidémiologiques et histopathologiques des tumeurs urogénitales au Cameroun. Progrès en Urologie, 16, 36-39.

[7] Siegel, R.L., Miller, K.D. and Jemal, A. (2016) Cancer Statistics, 2016. CA: A Cancer Journal for Clinicians, 66, 7-30.

[8] Raz, R. (2011) Urinary Tract Infection in Postmenopausal Women. Korean Journal of Urology, 52, 801-808. https://doi.org/10.4111/kju.2011.52.12.801

[9] Karmouni, T., Patard, J.J., Bensalah, K., Manunta, A., Guillé, F. and Lobel, B. (2001) Prise en charge urologique des traumatismes iatrogènes de l'uretère. Progrès en Urologie, 11, 642-646.

[10] Conort, P., Doré, B. and Saussine, C. (2004) Prise en charge urologique des calculs rénaux et urétéraux de l'adulte. Progrès en Urologie, 14, 1096-1102.

[11] Kambou, T., Ouattara, A., Zare, C., Ouattara, A.M., Pare, A.K. and Sanon, B.G. (2014) Traumatismes urogénitaux: Profil épidémiologique et aspects lésionnels au centre hospitalier universitaire souro sanon de Bobo dioulasso (burkina faso). URO'ANDRO, 1, 83-90. 